\title{
Comparing Analgesic Efficacy of Regional Block Techniques After Laparoscopic Liver Resection [Letter]
}

\author{
Nong He (D), Fu-Shan Xue (D), Cheng-Wen Li (D) \\ Department of Anesthesiology, Beijing Friendship Hospital, Capital Medical University, Beijing, People's Republic of China
}

Correspondence: Fu-Shan Xue, Department of Anesthesiology, Beijing Friendship Hospital, Capital Medical University, No. 95 Yong-An Road, Xi-Cheng District, Beijing, 100050, People's Republic of China, Tel +86 1391 I 177655, Fax +86 10-63138362, Email xuefushan@aliyun.com; fushanxue@outlook.com

\section{Dear editor}

The recent article of Kang et al ${ }^{1}$ comparing analgesic efficacy of erector spinae plane block (ESPB) and posterior quadratus lumborum block (PQLB) after laparoscopic liver resection in a randomized controlled trial was of great interest. They concluded that two regional blocks provided similar postoperative analgesia. However, we would like to remind the readers of several issues in the design and results of this study and wish to invite the authors to comment.

First, primary outcome of this study was cumulative opioid consumption in the first postoperative $24 \mathrm{~h}$. The sample size calculation was based on the findings of a previous study ${ }^{2}$ and their retrospective data, by which the calculated mean \pm standard deviation of IV morphine equivalents (IME) for cumulative opioid consumption in the first postoperative $24 \mathrm{~h}$ was $45.5 \pm 21.8 \mathrm{mg}$. Furthermore, the authors considered that a $30 \%$ reduction of mean IME in the PQLB group compared to the ESPB group was a clinically important difference. According to available literature, however, the recommended minimal clinically important difference of postoperative cumulative opioid consumption is an absolute reduction of 10 mg morphine in the IME for $24 \mathrm{~h}^{3}$ As the expected minimal clinically important difference of primary outcome between groups in this study is significantly larger than the recommended value in the literature, we cannot exclude the possibility of insufficient power to show the significant difference of primary outcome between groups.

Second, other than PQLB and ESPB, a standardized supplemental analgesic regimen was also used for postoperative pain control. It is generally believed that satisfactory postoperative pain control should achieve a numerical rating scale (NRS) score of 3 or less. ${ }^{4}$ According to Figure 2 of Kang et al's article, ${ }^{1}$ we noted that the means of postoperative resting pain NRS scores in the PACU stay, and at $24 \mathrm{~h}$ and $48 \mathrm{~h}$ after surgery in the two groups were more than 4, with large standard deviations. Even the means of highest postoperative resting pain NRS scores during the PACU stay in the two groups were more than 6 . These results indicate that a significant number of patients experienced moderate to severe postoperative resting pain within $48 \mathrm{~h}$ after surgery. Furthermore, it is conceivable that pain intensity on active status will be more severe, though this study did not evaluate this variable. Actually, in this study, the proportion of patients who were "satisfied" and "very satisfied" with pain relief at $24 \mathrm{~h}$ after surgery was only $71-79 \%$. This is not ideal postoperative pain control for the successful use of enhanced recovery after surgery protocols, in which multimodal analgesic regimen is recommended and analgesics should be universally titrated to achieve minimal postoperative pain, ie, a pain NRS score of 3 or less. ${ }^{4}$

Finally, this study observed the cumulative opioid consumption, resting pain VAS scores and the occurrence of nausea or vomiting at $24 \mathrm{~h}, 48 \mathrm{~h}$ and $72 \mathrm{~h}$ after surgery, but it only assessed the Quality of Recovery-15 (QoR-15) scores at $24 \mathrm{~h}$ after surgery. The available evidence indicates that measurement of the QoR-15 score on the day of surgery may not be reliable. ${ }^{5}$ Most important, mean QoR-15 scores at $24 \mathrm{~h}$ after surgery in the two groups were only about $73 \%$ of preoperative baselines, indicating a poor quality of early postoperative recovery. As the QoR-15 score was only assessed 
at a single time point, moreover, an important issue that this study cannot answer is whether the PQLB and ESPB groups were comparable with respect to the quality of recovery after first postoperative $24 \mathrm{~h}$. Given the facts that the QoR-15 questionnaire has good acceptability and feasibility in clinical practice and most patients can complete the questionnaire in less than 3 min, ${ }^{6}$ we suggest that the QoR-15 score should be repeatedly assessed at the time points after first postoperative $24 \mathrm{~h}$, if the quality outcomes of enhanced recovery after surgery protocols are the measured variables of study design.

\section{Disclosure}

All authors have no financial support and report no potential conflicts of interest for this communication.

\section{References}

1. Kang R, Lee S, Kim GS, et al. Comparison of analgesic efficacy of erector spinae plane block and posterior quadratus lumborum block in laparoscopic liver resection: a randomized controlled trial. J Pain Res. 2021;14:3791-3800. doi:10.2147/JPR.S343366.

2. Kim D, Kim JM, Choi GS, Heo G, Kim GS, Jeong JS. Ultrasound-guided erector spinae plane block for postoperative analgesia in laparoscopic liver resection: a prospective, randomised controlled, patient and observer-blinded study. Eur J Anaesthesiol. 2021;38(Suppl 2):S106-S112. doi:10.1097/ EJA.0000000000001475

3. Laigaard J, Pedersen C, Rønsbo TN, Mathiesen O, Karlsen APH. Minimal clinically important differences in randomised clinical trials on pain management after total hip and knee arthroplasty: a systematic review. Br J Anaesth. 2021;126(5):1029-1037. doi:10.1016/j.bja.2021.01.021.

4. Mancel L, Van Loon K, Lopez AM. Role of regional anesthesia in Enhanced Recovery After Surgery (ERAS) protocols. Curr Opin Anaesthesiol. 2021;34(5):616-625. doi:10.1097/ACO.0000000000001048.

5. Chazapis M, Walker EM, Rooms MA, Kamming D, Moonesinghe SR. Measuring quality of recovery-15 after day case surgery. Br $J$ Anaesth. 2016;116(2):241-248. doi:10.1093/bja/aev413.

6. Stark PA, Myles PS, Burke JA. Development and psychometric evaluation of a postoperative quality of recovery score: the QoR-15. Anesthesiology. 2013;118(6):1332-1340. doi:10.1097/ALN.0b013e318289b84b.

Dove Medical Press encourages responsible, free and frank academic debate. The content of the Journal of Pain Research 'letters to the editor' section does not necessarily represent the views of Dove Medical Press, its officers, agents, employees, related entities or the Journal of Pain Research editors. While all reasonable steps have been taken to confirm the content of each letter, Dove Medical Press accepts no liability in respect of the content of any letter, nor is it responsible for the content and accuracy of any letter to the editor.

Journal of Pain Research

\section{Dovepress}

\section{Publish your work in this journal}

The Journal of Pain Research is an international, peer reviewed, open access, online journal that welcomes laboratory and clinical findings in the fields of pain research and the prevention and management of pain. Original research, reviews, symposium reports, hypothesis formation and commentaries are all considered for publication. The manuscript management system is completely online and includes a very quick and fair peer-review system, which is all easy to use. Visit http://www.dovepress.com/testimonials.php to read real quotes from published authors.

Submit your manuscript here: https://www.dovepress.com/journal-of-pain-research-journal 